\title{
Optimising Conservation of Artworks, Energy Performance and Thermal Comfort Combining Hygrothermal Dynamic Simulation and On-Site Measurements in Historic Buildings
}

\author{
Francesca Frasca $^{1}$, Elena Verticchio ${ }^{2}$, Cristina Cornaro $^{3}$, Anna Maria Siani ${ }^{1}$ \\ ${ }^{1}$ Department of Physics, Sapienza Università di Roma, Rome, Italy \\ ${ }^{2}$ Department of Earth Sciences, Sapienza Università di Roma, Rome, Italy \\ ${ }^{3}$ Department of Enterprise Engineering, Università degli Studi di Roma "Tor Vergata", Rome, Italy
}

\begin{abstract}
The indoor climate conditions being suitable for the conservation of cultural heritage can be conflicting with energy saving and thermal comfort. Moreover, the moisture dynamics have not been studied enough in the simulation of the indoor environment, even though its interaction with artworks is crucial in deterioration phenomena. This research aims at defining a strategy, based on experimental data and dynamic simulation of hygrothermal behaviour, in order to design a HVAC system able to simultaneously satisfy conservation, thermal comfort and energy requirements. A weighted function for the multi-objective optimization has been proposed and effectively used to pinpoint the combination of temperature and relative humidity set-points.
\end{abstract}

\section{Introduction}

A thorough diagnosis of the interactions between indoor climate and materials is crucial to define efficient climate control strategies for the preventive conservation of Cultural Heritage.

Indoor climate measurements combined with the wholebuilding dynamic simulation, have been proven effective in the in-depth understanding of the indoor climate and of the object-environment and building-environment interactions (Lucchi et al., 2018). Measurements of temperature and relative humidity allow to investigate the current indoor climate, to understand the on-going deterioration processes, if any, and to define the associated empirical dose-response functions. Dynamic simulation can be employed to plan conservation actions with the aim to reduce the damage risk induced by inadequate temperature and relative humidity conditions. Testing new climate control strategies is particularly important in historic buildings, as it is usually not possible to refurbish the envelope due to their historic value and aesthetic aspect (Mazzarella, 2015). So far, the dynamic simulation of temperature, relative humidity and moisture content within multi-layered building elements (O'Leary et al., 2015) has been mainly carried out to investigate on the effect of humidity on the building materials' durability, the energy consumption and human health (e.g. Barclay et al., 2014; Vereecken et al., 2015; Hansen et al., 2018). On the contrary, few studies have been conducted using the hygrothermal analysis to assess the conservation of materials, such as artworks. A comprehensive overview of the problems and methods in the energy retrofitting of historic/traditional buildings is given by Webb (2017).

The relative humidity plays a key role in all the deterioration phenomena affecting vulnerable hygroscopic materials, such as wood, paper, textile, etc. (Camuffo, 2014). Therefore, simulation models, for humidity cycles and condensation processes, can effectively improve conservation strategies.

The capability to predict the indoor microclimate offers the chance to investigate on integrated solutions that concurrently fulfil different needs. So far, only Schito et al. (2018) have proposed a multi-objective optimisation of the HVAC (Heating Ventilation and Air-Conditioning) system combining the minimisation of the energy cost and the visitors' discomfort with the accomplishment of conservation requirements. In that study, a damage function based on Michalski (2002) was used to prevent the future chemical damage to the collections. Kompatscher et al. (2018) have compared the impact on conservation risks of various climate control strategies recommended by technical standards and guidelines. Neither of the two above studies have focused on the identification of adequate hygrothermal conditions with the aim of mitigating the observed deterioration in the material.

The purpose of this research is to investigate on a possible control climate configuration of the HVAC system using a multi-objective function, which can synthetize conflicting issues in a weighted function. The function is multi-objective as it integrates the concomitant minimisation of the damage risk, the thermal discomfort and the energy consumption in historic buildings.

The hygrothermal analysis was used to thoroughly study the indoor climate by coupling climate measurements and the whole-building dynamic simulation. The latter includes a one-dimensional transfer model of heat air and moisture across opaque components in order to accurately simulate the hygrometric response of the environment over time.

The mechanical risk assessment of the wooden artefacts was based on an empirical dose-response relationship derived from experimental data on climate-induced cracks observed on the objects.

The proposed methodology was applied to the Archaeological Museum of Priverno with the aim to test 
the summer climate control strategy. The preliminary results are presented and discussed in this paper.

\section{The case study}

This paper concerns with the Archaeological Museum of Priverno (Lat. $41.5^{\circ}$ and Long. $13.2^{\circ}$ ), housed in a threefloored historic building (13 ${ }^{\text {th }}$ century) located at about $70 \mathrm{~km}$ SE far from Rome (Italy). The building is oriented in the SW-NE direction with respect to the main entrance and consists of thirteen exhibition rooms and three other rooms (the total number of zones is sixteen) deployed between the first and second floor, with an internal courtyard and a terrace in the north-west side. A HVAC system only for temperature control is turned on during the opening hours by staff from November till April (heating) and from June till August (cooling). However, low temperatures in winter and unpleasant warm temperatures in summer are often experienced indoors by visitors and staff. This site preserves valuable wooden ceilings decorated with oil paintings and a collection of sculptures, jewellery and pottery excavated in the close archaeological area. The wooden ceilings were restored in 2012 as they suffered mechanical degradation (i.e. swelling and shrinkage due to moisture absorption and desorption) visible in terms of panels' deformations, detachments of the painted-layer and cracks along the tangential direction of wood panels (Figure 1). However, since cracks and deformations have been visible, they were monitored over the period of this study.

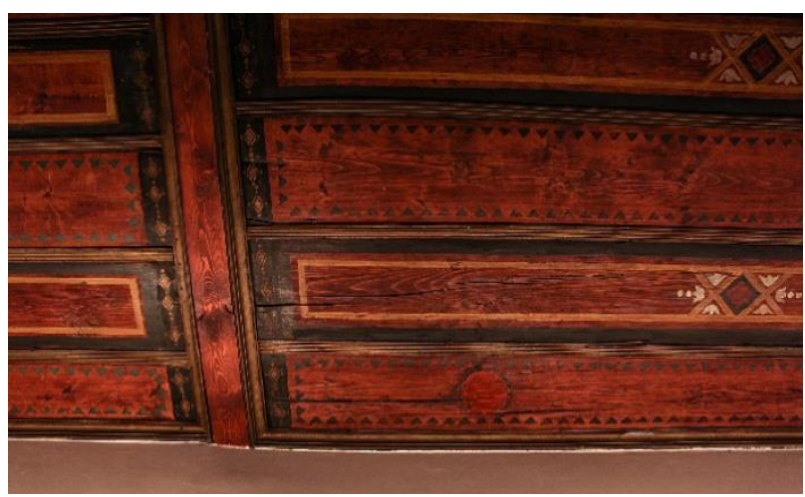

Figure 1: Detail of the wooden ceiling decorated with oil paintings on the second floor (picture taken in 2016).

Cracks are visible along the tangential direction of wood panels.

For the above purpose, a monitoring campaign of indoor and outdoor climate and of crack-width in the wooden ceiling was conducted for 15-months (August 2016 November 2017).
A preliminary analysis, based on the dynamic simulation of the building and the HVAC system, has shown that switching from the current setting to a continue temperature control over the year would improve visitors' comfort and reduce the occurrences of seasonal and daily crack-width fluctuations (i.e. stress-and-strain cycles). Nevertheless, it was found that due to the absence of control over RH the allowable T-RH limits suggested by the American guidelines ASHRAE 2011 for the conservation of artworks were not met (Frasca et al., 2019).

Therefore, a HVAC system equipped with a humidity control device was proposed to further reduce mechanical degradation risks.

\section{Methods}

The research was conducted using both on-site measurements and whole-building dynamic simulation. The workflow of the research can be schematised in three steps as shown in Figure 2:

1. the derivation of a empirical dose-response relationship from long-term measurements of indoor climate and identification of the degradation marker;

2. the hygrothermal assessment through the whole building dynamic simulation;

3. the definition of a single-weighted function for the multi-objective optimization of the indoor climate combining artworks' conservation needs, the energy saving and the thermal comfort.

\section{The monitoring campaign of the indoor climate and the damage marker}

The monitoring campaign of the main indoor climate variables was carried out from August 2016 to November 2017. The measurement system in room 9 consisted of two temperature $(\mathrm{T})$ and relative humidity $(\mathrm{RH})$ probes, an air-surface thermometer $\left(\mathrm{T}_{\mathrm{s}}\right)$ and a crack-width $(\mathrm{C})$ meter installed on a panel of the wooden ceiling. Other two T-RH probes were installed in room 4 and 10 with the aim to characterise the microclimate in different sites of the building. Moreover, a T-RH probe was placed outside in order to study the influence of outdoor climate on the indoors and to build a custom weather file to be used in the simulation environment.

The list of sensors and their technical features are reported in Table 1. The metrological features of $\mathrm{T}$ and $\mathrm{RH}$ sensors are in accordance with the uncertainties suggested by the European standards EN 15758:2010 and EN 16242:2012.

Table 1: The technical features of sensors used within the monitoring campaign.

\begin{tabular}{|c|c|c|c|c|}
\hline & $\mathbf{T}$ & $\mathbf{R H}$ & $\mathbf{T}_{\mathbf{s}}$ & $\mathbf{C}$ \\
\hline Sensor & $\begin{array}{c}\text { Resistance } \\
\text { Pt100 1/3 DIN }\end{array}$ & $\begin{array}{c}\text { Film capacitor } \\
\text { Rotronic C94 }\end{array}$ & Thermistor NTC & $\begin{array}{c}\text { Potentiometer in conductive } \\
\text { plastic }\end{array}$ \\
\hline Operating range & $-40{ }^{\circ} \mathrm{C}$ to $+60{ }^{\circ} \mathrm{C}$ & 0 to $100 \%$ & $-30{ }^{\circ} \mathrm{C}$ to $+150{ }^{\circ} \mathrm{C}$ & $10 \mathrm{~mm}$ \\
\hline Uncertainty & $\pm 0.3{ }^{\circ} \mathrm{C}$ & $+1.5 \%$ & $\pm 0.1{ }^{\circ} \mathrm{C}$ & $+0.025 \mathrm{~mm}$ \\
\hline
\end{tabular}


Actual Building

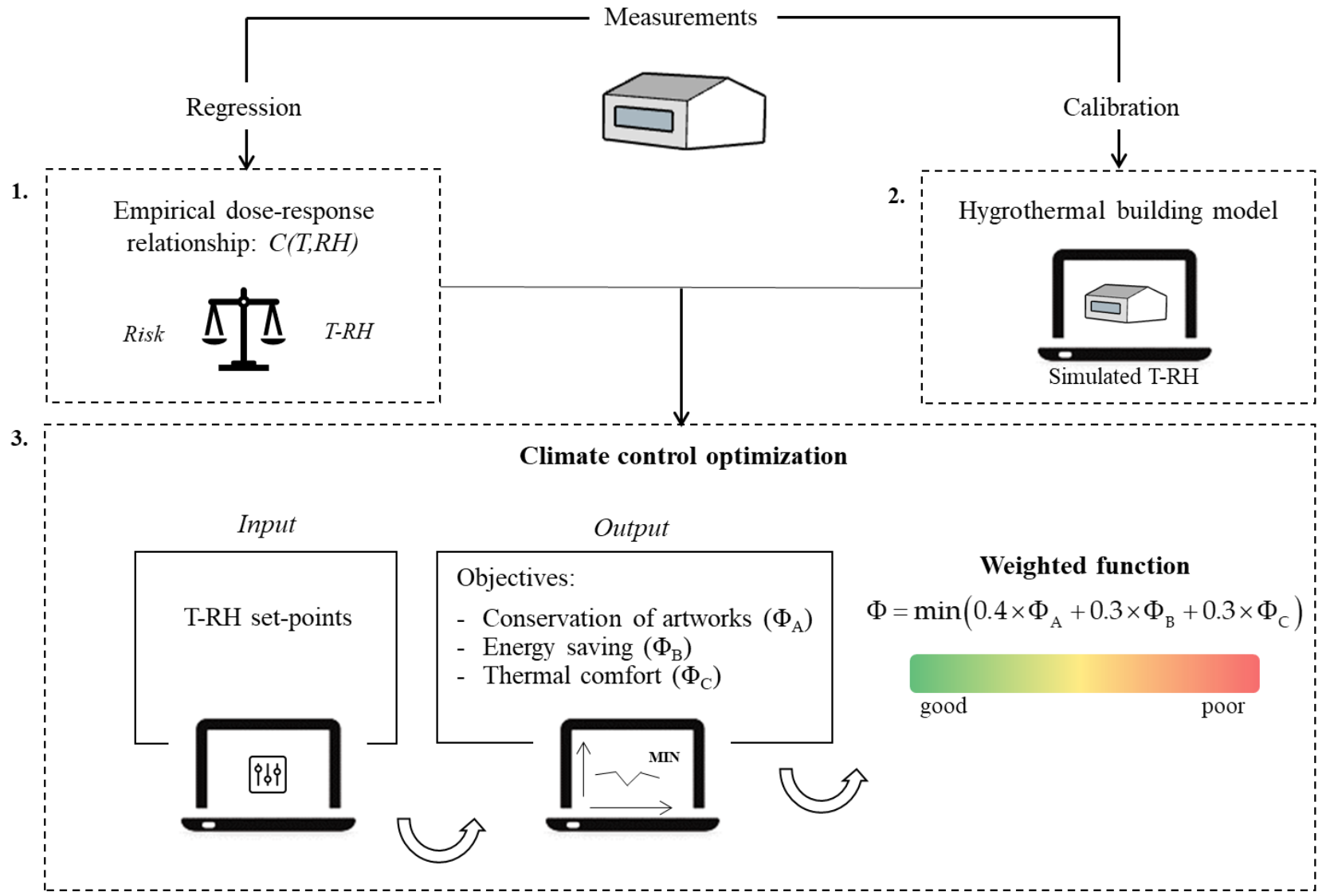

Figure 2: Schematic flow chart of the multi-objective optimization proposed in this paper.

The parameter $\mathrm{C}$ was used as damage marker for the mechanical degradation of the wooden ceilings. An empirical dose-response relationship was derived from a production function based on a non-linear multiple regression between the modelled crack $\left(\mathrm{C}_{\mathrm{m}}\right)$ behaviour and the hygrothermal conditions at the air-surface interfaces:

$$
C_{m}=a \times R H_{\mathrm{s}}^{\mathrm{b}} \times T_{\mathrm{s}}^{\mathrm{c}}
$$

where $\mathrm{a}=6.5 \mathrm{~mm} \times\left(100^{-\mathrm{b}}\right) \times\left({ }^{\circ} \mathrm{C}^{-\mathrm{c}}\right), \mathrm{b}=-5.4 \times 10^{-2}$ and $\mathrm{c}=-4.0 \times 10^{-5} \cdot \mathrm{RH}_{\mathrm{s}}$ is the relative humidity at the interface between the surface and the air layer computed from mixing ratio (MR) of moist air and surface temperature $\left(\mathrm{T}_{\mathrm{s}}\right)$. MR was calculated from $\mathrm{T}$ and $\mathrm{RH}$ readings using the equation reported in the EN 16242:2012 and taking into account the standard value of the atmospheric pressure (1013 $\mathrm{hPa})$.

The uncertainty associated to the derived variables (MR and $\mathrm{RH}_{\mathrm{s}}$ ) was estimated by applying the propagation of error (Cohen, 1998) based on the uncertainties of experimental measurements. The MR uncertainty was $0.3 \mathrm{~g} / \mathrm{kg}$, computed from $\mathrm{T}$ and $\mathrm{RH}$ uncertainties; the uncertainty of $\mathrm{RH}_{\mathrm{s}}$ was $4.6 \%$ derived from the MR uncertainty and the air-surface thermometer uncertainty. Finally, the uncertainty of $\mathrm{C}_{\mathrm{m}}$ was $0.024 \mathrm{~mm}$, calculated from $\mathrm{T}_{\mathrm{s}}$ and $\mathrm{RH}_{\mathrm{s}}$ uncertainties.

The coefficient of determination $\left(\mathrm{R}^{2}\right)$ was 0.89 , showing the goodness of $\mathrm{C}_{\mathrm{m}}$ fit on the experimental $\mathrm{C}$ data; the root-mean-square-error (RMSE) was $0.014 \mathrm{~mm}$, i.e. less than the uncertainty of the crack-width meter.

\section{The simulation environment}

Dynamic building simulation of the indoor climate was performed using the IDA Indoor Climate and Energy 4.8 (IDA ICE) developed and distributed by EQUA simulation $\mathrm{AB}$. For the modelling of room 9, IDA ICE was extended with the HMWall model, that implements a one-dimensional heat air and moisture transfer model across porous materials. The HMWall model was meticulously tested by the authors using exercises at increasing complexity and the preliminary results are reported in (Frasca et al., 2018).

Our purpose was to calibrate the building envelope when the HVAC system was not in operation. Thus, the calibration was performed in May and the validation procedures were carried out in September/October. Since the thresholds of the statistical parameters for the calibration with hourly T-RH data were not available in the literature, the uncertainty of T-RH measurements was assumed as rejection criteria. The closer is the parameter to the sensor uncertainty, the better the building model reproduces the actual building. The calibration procedure consisted of:

- a first automatic step for the thermal behaviour of the whole building model;

- a second manual step integrating the moisture transport across the walls (HMWall) of room 9. 
The geometry of the building model of the Museum was created starting from the architectural survey and using a wall composition comparable to the construction techniques used in lower Latium in the Middle Age. The wall composition was assumed to be unchanged over time except for the ceilings. The building model included sixteen zones but only room 9 (Figure 3 ) was considered for the hygrothermal assessment with the HMWall model.

The weather file used to run the model was created from outdoor $\mathrm{T}$ and $\mathrm{RH}$ values measured outside the building. The weather file also included global horizontal solar irradiance and wind speed and direction measured at the ARSIAL (Agenzia Regionale per lo Sviluppo e l'Innovazione dell'Agricoltura del Lazio) meteorological station in Maenza (Lat. $41.5^{\circ}$ and Long. $13.2^{\circ}$ ).

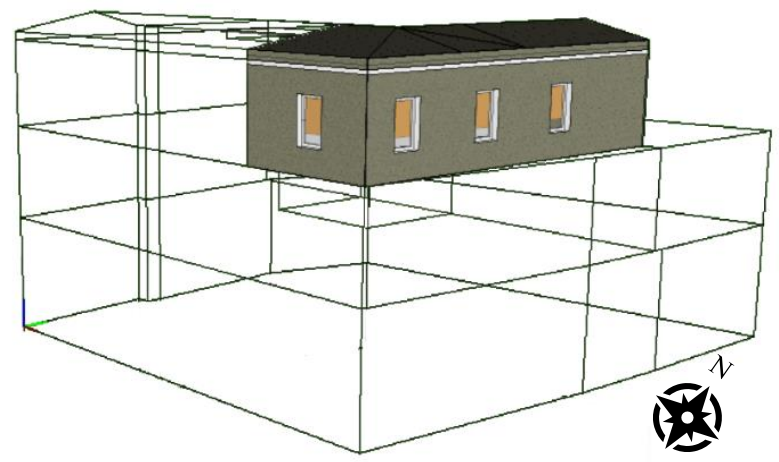

Figure 3: 3D model of the room 9 sketched in IDA ICE.

The automatic calibration of the whole building was carried out to fine-tune the input parameters of the envelope, such as the wall thermal transmittance (Uvalue), thermal bridges and the infiltration rate, which were unknown. The Sensitivity Analysis (SA) based on the Elementary Effect method (EEs) demonstrated that thermal bridges and infiltration highly affected modelled $\mathrm{T}$ and RH data. Then, the Particle Swarm Optimization General Pattern Search of Hooke-Jeeves (PSO-GPSHJ) genetic algorithm, implemented by GenOpt ${ }^{\circledR}$, was used to minimise the RMSE between modelled and measured indoor climate data. The PSO-GPSHJ is a hybrid algorithm, that combines a global search method (PSO) with a local search method (GPSHJ). The Parametric Run extension was used to communicate GenOpt ${ }^{\circledR}$ with IDA ICE. A RMSE of $0.4{ }^{\circ} \mathrm{C}$ for $\mathrm{T}$ and of $2.0 \%$ for $\mathrm{RH}$ was found.

The second step of calibration was manually performed on room 9 to fine-tune the hygrothermal properties of opaque components, such as the thermal conductivity $(\lambda)$, the equilibrium water content at $80 \%$ of relative humidity $\left(\mathrm{w}_{80}\right)$ and the water absorption coefficient $\left(\mathrm{A}_{\mathrm{w}}\right)$. Table 2 summarises the main statistic parameters about the calibration and validation performed to model room 9 .

It was found that room 9 is well calibrated with the following features:

- a floor area of $62 \mathrm{~m}^{2}$ and a volume area of $185 \mathrm{~m}^{3}$;

- three external walls of $0.6 \mathrm{~m}$;

- a thermal transmittance (U-value) of $1.4 \mathrm{~W} \mathrm{~m}^{-2} \mathrm{~K}^{-1}$;
- an adiabatic internal wall of $0.6 \mathrm{~m}$ with a U-value of $1.1 \mathrm{~W} \mathrm{~m}^{-2} \mathrm{~K}^{-1}$;

- an adiabatic floor with a U-value of $2.7 \mathrm{~W} \mathrm{~m}^{-2} \mathrm{~K}^{-1}$;

- an internal wooden ceiling of $0.08 \mathrm{~m}$ with a U-value of $3.5 \mathrm{~W} \mathrm{~m}^{-2} \mathrm{~K}^{-1}$;

- thermal bridges higher than $0.5 \mathrm{~W} \mathrm{~m}^{-1} \mathrm{~K}^{-1}$;

- a fixed infiltration at $0.02 \mathrm{ACH}$;

- a glazing system with wooden-framed low-emission double panes (6-12-6 mm filled with air) characterised by a U-value of $1.6 \mathrm{~W} \mathrm{~m}^{-2} \mathrm{~K}^{-1}$ and a solar heat gain coefficient (SHGC) of 0.4. All windows have an area of $1.5 \mathrm{~m}^{2}$ and are covered by black interior roller shades.

The internal opaque components were modelled assuming to be in dynamic equilibrium with air at $\mathrm{RH}=50 \%$ (adjacent room) and $\mathrm{RH}=55 \%$ (crawl space).

Table 2: Summary of the calibration and validation statistics of air temperature $(T)$ and relative humidity $(R H)$ in room 9. $M A E=$ mean absolute error; $R M S E=$ root mean square error; $C V$-RMSE = coefficient of variation of RMSE with respect to the average; $r_{s}=$ Spearman's rank correlation coefficient.

\begin{tabular}{|c|c|c|c|c|}
\hline & \multicolumn{4}{|c|}{ Calibration } \\
\hline & $M A E$ & $R M S E$ & $C V-R M S E$ & $r_{s}$ \\
\hline $\mathbf{T}$ & $0.2{ }^{\circ} \mathrm{C}$ & $0.3{ }^{\circ} \mathrm{C}$ & $1.2 \%$ & 1.0 \\
\hline $\mathbf{R H}$ & $0.8 \%$ & $1.0 \%$ & $2.0 \%$ & 0.9 \\
\hline & \multicolumn{4}{|c|}{ Validation } \\
\hline & $M A E$ & $R M S E$ & $C V-R M S E$ & $r_{s}$ \\
\hline $\mathbf{T}$ & $0.2{ }^{\circ} \mathrm{C}$ & $0.3{ }^{\circ} \mathrm{C}$ & $1.2 \%$ & 1.0 \\
\hline $\mathbf{R H}$ & $1.0 \%$ & $1.2 \%$ & $2.4 \%$ & 0.7 \\
\hline
\end{tabular}

\section{The multi-objective optimization}

The optimization aimed at finding the T and RH set-points of a generic HVAC system able to control both the parameters in summertime. July was chosen as the summer reference month, when the artwork preservation, the energy saving and the human comfort may be strongly conflicting (Schito et al., 2018).

Three specific quantities were defined in order to estimate the quality of the environment in terms of conservation needs $\left(\Phi_{\mathrm{A}}\right)$, energy consumptions $\left(\Phi_{\mathrm{B}}\right)$ and thermal comfort of people $\left(\Phi_{\mathrm{C}}\right)$.

$$
\begin{gathered}
\Phi_{A}=\frac{\sum\left(\Delta C>\Delta C_{\text {risk }}\right)}{N_{d}} \\
\Phi_{B}=\frac{\int_{0}^{t} Q(t) d t}{\int_{0}^{t} Q_{\max }(t) d t} \\
\Phi_{C}=\frac{P D H}{h_{o c c} \times n_{o c c}}=\frac{P D D \times h_{o c c} \times n_{o c c}}{h_{o c c} \times n_{o c c}}
\end{gathered}
$$

$\Phi_{\text {A }}$ (Eq. 2) takes into account Eq. 1 to evaluate the daily stress-and-strain cycle of the wooden ceiling. $\Phi_{\mathrm{A}}$ is defined as the ratio between the occurrences of the maximum daily span of $\mathrm{C}\left(\Delta \mathrm{C}=\mathrm{C}_{\max }-\mathrm{C}_{\min }\right)$ exceeding $\Delta \mathrm{C}_{\text {risk }}(=0.03 \mathrm{~mm})$ and the total number of days $\left(\mathrm{N}_{\mathrm{d}}\right)$ under study. Since the stress-and-strain cycle is cumulative, $\Delta \mathrm{C}_{\text {risk }}$ was defined so that the maximum daily fluctuations of $\mathrm{C}$ were kept at the minimum, assumed close to the sensor's uncertainty. This meant that $\Phi_{\mathrm{A}}$ is 
zero when $\Delta \mathrm{C}$ is less than $\Delta \mathrm{C}_{\text {risk }}$ over $\mathrm{N}_{\mathrm{d}}$ and is equal to unity when $\Delta \mathrm{C}$ is always higher than $\Delta \mathrm{C}_{\text {risk }}$.

$\Phi_{\mathrm{B}}$ (Eq. 3) is the ratio between the total energy consumption $(\mathrm{Q}$, i.e. sum of both heating and cooling demands) and the maximum total energy consumption $\left(\mathrm{Q}_{\max }\right.$, estimated as the nominal power of the system multiplied by the total number of hours under study). It is zero when the system is always turned off and is equal to the unity when it is always turned on at the maximum power.

$\Phi_{\mathrm{C}}$ (Eq. 4) is the predicted total amount of discomfort hours (PDH), computed as the product among PPD (Percentage of Person Dissatisfied), the number of occupants $\left(\mathrm{n}_{\mathrm{occ}}\right)$ and the occupancy hours $\left(\mathrm{h}_{\mathrm{occ}}\right)$. Ten visitors were considered during the opening hours (10-13 and 14-18) from Wednesday till Sunday (about 22 days in July). The metabolic activity value was set to 1.5 MET, i.e. equivalent to $87 \mathrm{~W} \mathrm{~m}^{-2}$ and corresponding to a standing-walking activity (EN 15251:2007); whereas, the clothing factor was set to 0.5 clo $\left(\sim 0.08 \mathrm{~m}^{2} \mathrm{~K} \mathrm{~W}^{-1}\right)$. $\Phi_{\mathrm{C}}$ is zero when $\mathrm{PDH}=0 \mathrm{~h}$ and is equal to unity when the discomfort is always experienced, i.e. $\mathrm{PDH}=1540 \mathrm{~h}$.

The three quantities were linearly combined in a weighted function $\Phi($ Eq. 5) so that limits range between 0 (bestcompromise solution) and 1 (worst-compromise solution).

$$
\Phi=\min \left(0.4 \times \Phi_{A}+0.3 \times \Phi_{B}+0.3 \times \Phi_{C}\right)
$$

The highest coefficient was given to $\Phi_{\mathrm{A}}$ in order to assign priority to conservation as recommended by the Italian Legislative Decree 192/2005 for historic buildings. Nevertheless, the weights were chosen to keep significant the contribution of $\Phi_{\mathrm{B}}$ and $\Phi_{\mathrm{c}}$ to the final score.

The control strategies for $\mathrm{T}$ and $\mathrm{RH}$ were defined in order to combine different $\mathrm{T}$ and $\mathrm{RH}$ set-points, by running a total of 30 simulations. T and RH set-points were selected starting from the recommendations given by the American guidelines ASHRAE (2011). T set-points ranged from $21{ }^{\circ} \mathrm{C}$ to $26^{\circ} \mathrm{C}$ at step of $1{ }^{\circ} \mathrm{C}$; whereas $\mathrm{RH}$ set-points ranged from $40 \%$ to $60 \%$ at step of $5 \%$. The HVAC system was modelled with the following components: an economizer, a pre-heating coil, an adiabatic evaporative humidifier, a cooling coil, a postheating coil and exhaust/supply fans. The economizer was introduced to mix fresh (outdoor) and exhaust (indoor) air depending on the carbon dioxide $\left(\mathrm{CO}_{2}\right)$ concentration with the aim of guaranteeing an acceptable indoor air quality $\left(\mathrm{CO}_{2}<1000 \mathrm{ppm}\right)$. The system was set with a variable air volume (VAV) to adjust the airflow depending on the actual T-RH condition and their distance from the selected set-points within $\pm 1{ }^{\circ} \mathrm{C}$ and $\pm 5 \%$ tolerances. The minimum and maximum values of airflows ranged between 55 litres/s and 431 litres/s. This allowed both to limit energy consumption and to not turn off the system, avoiding any abrupt change in the indoor climate related to the system on/off. The nominal power of the HVAC system was set to $20 \mathrm{~kW}$ per day.

\section{Results and discussion}

The three quantities (Eqs. 2-4) were calculated from the outcomes of 30 simulations in July, as shown in Figure 4 by using carpet plots based on a colour code scale, from green (best condition) to red (worst condition). It can be noticed that the green conditions are experienced for each quantity in different T-RH set-points, so that an adequate compromise among them is not trivial to be found.

$\Phi_{\mathrm{A}}$ is equal to zero when the RH set-point is $45 \%$ and the $\mathrm{T}$ set-point is below $24{ }^{\circ} \mathrm{C}$, meaning that $\Delta \mathrm{C}$ values are less than $\Delta \mathrm{C}_{\text {risk. }}$ Besides, low $\Phi_{\mathrm{A}}$ values occur when the RH set-point is $40 \%$ or above $55 \%$ for the T set-point > $23{ }^{\circ} \mathrm{C}$. This confirms the importance of controlling both $\mathrm{T}-\mathrm{RH}$ parameters when the risk of conservation is one of the objectives of the retrofitting or the climate control strategy.

$\Phi_{\mathrm{B}}$ is green when the T set-point is closer to the outdoor thermal conditions. The minimum delivered energy of $890 \mathrm{kWh}$ occurs at set-points $\mathrm{T}=26^{\circ} \mathrm{C}$ and $\mathrm{RH}=55 \%$; whereas the maximum delivered energy of $4500 \mathrm{kWh}$ is found at set-points $\mathrm{T}=21^{\circ} \mathrm{C}$ and $\mathrm{RH}=40 \%$. In this case, the energy demands are mainly driven by $\mathrm{T}$ set-points.

Green $\Phi_{\mathrm{C}}$ values related to the thermal comfort occur when the $\mathrm{T}$ set-point is less than $23{ }^{\circ} \mathrm{C}$, in accordance with the European standard EN 15251:2007. Indeed, the PDH value is less than $15 \mathrm{~h}$ out of a total of $154 \mathrm{~h}$ of occupancy per person. The PDH value is tripled up to $46 \mathrm{~h}$ per person when the T set-point exceeds $25^{\circ} \mathrm{C}$.

\begin{tabular}{|c|c|c|c|c|c|c|}
\hline \multicolumn{7}{|c|}{$\Phi_{A}($ Conservation needs $)$} \\
\hline $\mathrm{RH}(\%)$ & 21 & 22 & 23 & 24 & 25 & 26 \\
\hline 40 & & & & & & \\
\hline 45 & & & & & & \\
\hline 50 & & & & & & \\
\hline 55 & & & & & & \\
\hline 60 & & & & & & \\
\hline \multicolumn{7}{|c|}{$\Phi_{B}($ Energy consumption $)$} \\
\hline $\mathrm{RH}(\%)$ & 21 & 22 & 23 & 24 & 25 & 26 \\
\hline 40 & & & & & & \\
\hline 45 & & & & & & \\
\hline 50 & & & & & & \\
\hline 55 & & & & & & \\
\hline 60 & & & & & & \\
\hline \multicolumn{7}{|c|}{$\Phi_{C}($ Thermal comfort $)$} \\
\hline $\mathrm{RH}(\%)$ & 21 & 22 & 23 & 24 & 25 & 26 \\
\hline 40 & & & & & & \\
\hline 45 & & & & & & \\
\hline 50 & & & & & & \\
\hline 55 & & & & & & \\
\hline 60 & & & & & & \\
\hline
\end{tabular}

Figure 4: Carpet plots of the three quantities used as objectives for the optimization of the T-RH set-points in the HVAC system. The colour code scale ranges between the minimum (green) and the maximum (red) values.

At this point, the weighted function $\Phi$ (Eq. 5) helps to find a compromise among these conflicting needs and, hence, to design a possible climate control strategy by means of the HVAC system. Figure 5 shows the carpet plot for $\Phi$ outcomes also including the percentage values. The best- 
compromise solutions are found when the T set-point is 22 or $23{ }^{\circ} \mathrm{C}$ and the $\mathrm{RH}$ set-point is $45 \%$ or when setpoint are $\mathrm{T}=24{ }^{\circ} \mathrm{C}$ and $\mathrm{RH}=60 \%$. On the contrary, the worst case is associated to T set-point of $26{ }^{\circ} \mathrm{C}$ and $\mathrm{RH}$ set-point of $50 \%$. It is worth to notice that $\Phi$ exceeds $25 \%$ when $\Phi_{\mathrm{A}}$ is maximum in conjunction with higher values of $\Phi_{\mathrm{B}}$ or $\Phi_{\mathrm{C}}$.

\begin{tabular}{|c|c|c|c|c|c|c|}
\hline \multicolumn{7}{|c|}{$\Phi$ (Weightedfunction) } \\
\hline $\mathrm{RH}(\%)$ & 21 & 22 & 23 & 24 & 25 & 26 \\
\hline 40 & $14 \%$ & $12 \%$ & $10 \%$ & $10 \%$ & $12 \%$ & $15 \%$ \\
\hline 45 & $8 \%$ & $7 \%$ & $7 \%$ & $18 \%$ & $22 \%$ & $26 \%$ \\
\hline 50 & $12 \%$ & $23 \%$ & $31 \%$ & $32 \%$ & $34 \%$ & $40 \%$ \\
\hline 55 & $30 \%$ & $28 \%$ & $22 \%$ & $21 \%$ & $13 \%$ & $18 \%$ \\
\hline 60 & $33 \%$ & $20 \%$ & $12 \%$ & $7 \%$ & $9 \%$ & $14 \%$ \\
\hline
\end{tabular}

Figure 5: Carpet plots of the weighted function (Eq. 5) used for the optimization of the T-RH set-points in the HVAC system. The colour code scale ranges between the best-compromise solution (green) and the worstcompromise solution (red). The values are reported on the plot as percentages.

The maximum daily span of the simulated T-RH and C were calculated as the difference between the maximum and minimum value of the day (i.e. $\Delta \mathrm{T}, \Delta \mathrm{RH}$ and $\Delta \mathrm{C}$, respectively) and are shown in Figure 6.

In the worst-compromise solution $(\Phi=40 \%), \Delta \mathrm{C}$ is on average slightly higher than $\Delta \mathrm{C}_{\text {risk}}$, even though indoor T$\mathrm{RH}$ values are within the tolerable limits of the HVAC system $\left(26 \pm 1{ }^{\circ} \mathrm{C}\right.$ and $\left.50 \pm 5 \%\right)$ and the daily spans are less than $2{ }^{\circ} \mathrm{C}$ and $6 \%$, respectively (Figure 6a). These hygrothermal conditions might be very risky for the conservation of the wooden ceiling, because the HVAC system introduces daily T-RH fluctuations to handle with the set-points. The response to the stress-and-strain cycle is a cumulative process and, although small, might induce an irreversible damage.

In the best configuration $(\Phi=7 \%), \Delta \mathrm{C}$ is always less 0.02 $\mathrm{mm}$ because indoor T-RH daily spans are less than $0.6{ }^{\circ} \mathrm{C}$ and $4 \%$ over the period, respectively (Figure $6 \mathrm{~b}$ ). Here, the delivered energy is $2500 \mathrm{kWh}$ and the $\mathrm{PDH}$ is $9 \mathrm{~h}$ per person.

Finally, $\Delta \mathrm{C}$ calculated from the two selected T-RH scenarios $\left(\Phi_{\max }=40 \%\right.$ and $\left.\Phi_{\min }=7 \%\right)$ were compared with the measured $\Delta \mathrm{C}$ in order to assess the effectiveness of the new climate control configurations. Figure 7 shows the $\Delta \mathrm{C}$ values as box-and-whiskers plots and the $\Delta \mathrm{C}_{\text {risk }}$ threshold as dashed horizontal line. In the current hygrothermal conditions (blue box), the maximum $\Delta \mathrm{C}$ value is $0.04 \mathrm{~mm}$, i.e. slightly above $\Delta \mathrm{C}_{\text {risk. }}$. The hypothesised climate control system would result to be riskier when $\Phi_{\max }$ is $40 \%$ (red box), as the average behaviour of the modelled $\Delta \mathrm{C}$ is significantly higher than that of the measured $\Delta \mathrm{C}$. On the contrary, when the $\Phi$ target reaches the minimum (green box), the modelled $\Delta \mathrm{C}$ values show an improvement. This hypothesis shows that the average behaviour of $\Delta \mathrm{C}$ is less than $0.01 \mathrm{~mm}$, suggesting that cumulative mechanical degradation processes have been potentially reduced. a)

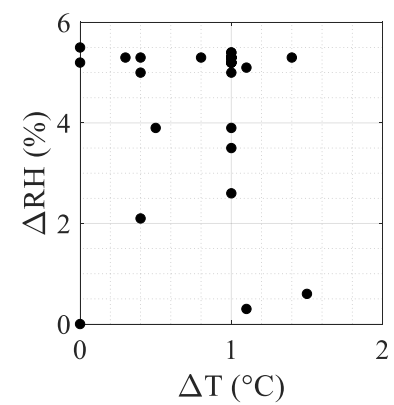

b)

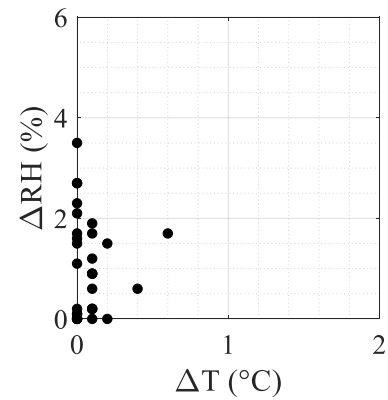

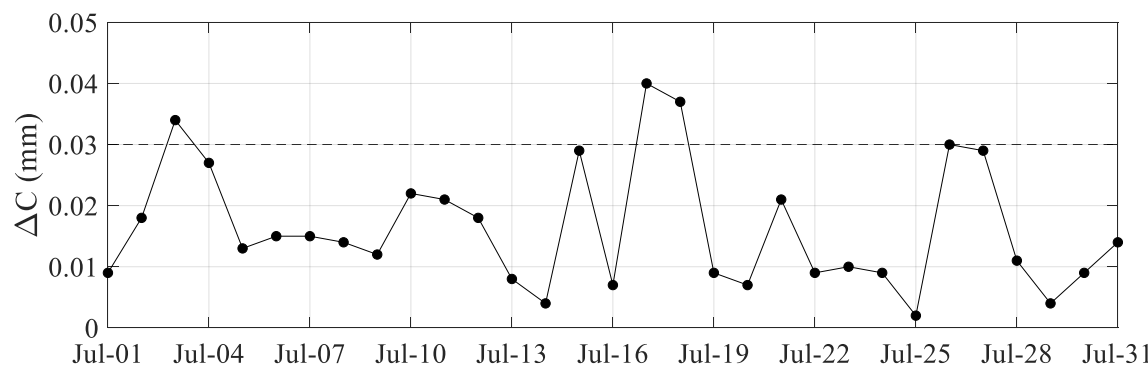

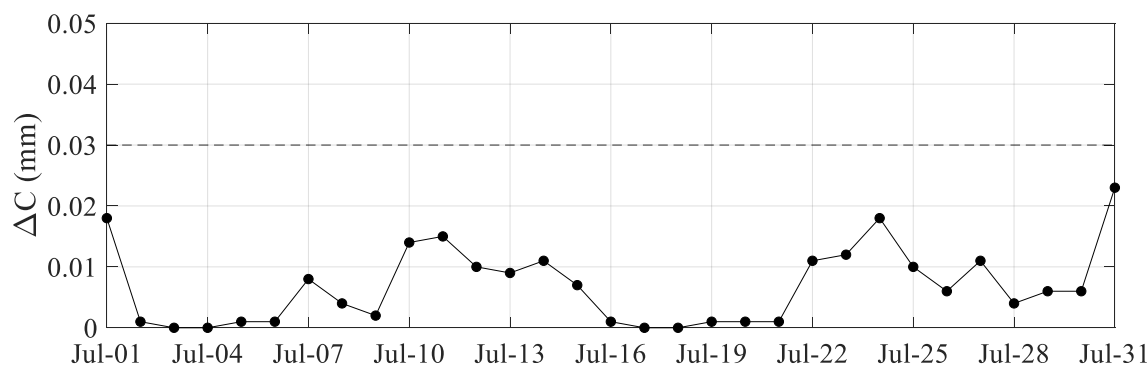

Figure 6: Scatter plot of the maximum daily spans ( $\Delta R H$ vs $\Delta T)$ of simulated $T$ and $R H$ and temporal behaviour of the maximum spans of cracks $(\Delta C):$ a) the worst-compromise solution of the weighted function $(\Phi=40 \%)$ and b) the bestcompromise solution $(\Phi=7 \%)$. 


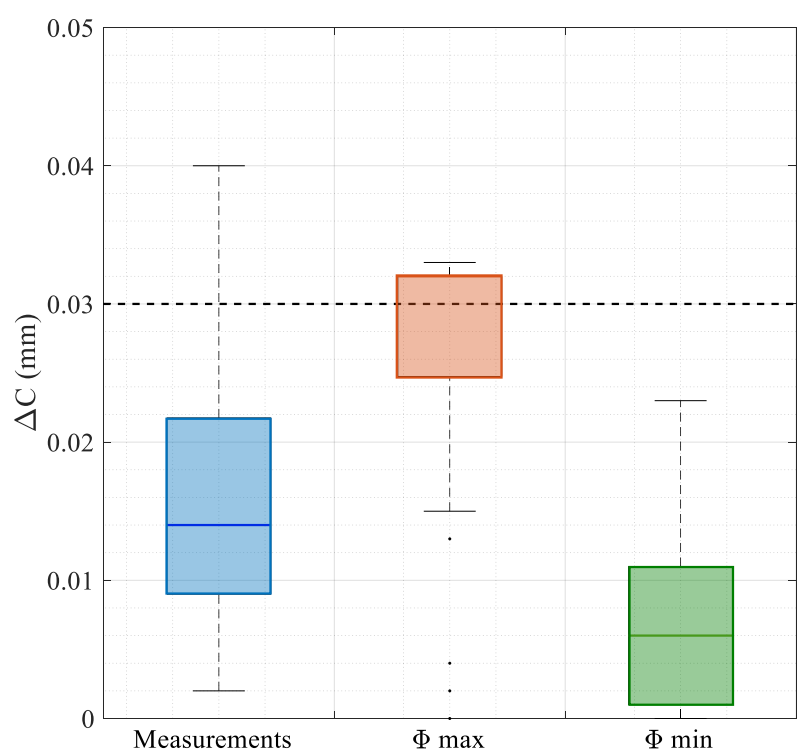

Figure 7: Box-and-whiskers plots of the daily fluctuations of cracks ( $\Delta C)$ : measurements (blue), the maximum of the weighted function $\Phi \max (\mathrm{red})$ and the minimum of weighted function $\Phi$ min (green). The dashed line is the $\Delta C_{\text {risk }}$ threshold $(0.03 \mathrm{~mm})$.

\section{Conclusions}

For the first time, a multi-objective optimization of a HVAC system within a historic building has been carried out by combining dynamic simulation with measurements of indoor climate parameters, and the damage marker of the wooden ceilings. In this study, the whole-building dynamic simulation software IDA ICE has the advantage to be integrated with a one-dimensional heat and moisture transfer model, the HMWall model, in order to thouroughly simulate the indoor moisture dynamics.

A weighted function $(\Phi)$ has been proposed and tested to identify an appropriate compromise solution between conservation of artworks, energy saving and thermal comfort requirements by comparing different combinations of temperature and relative humidity setpoints. These preliminary outcomes support the importance to carefully choose the T-RH set-points. Even though the current hygrothermal conditions seem to not be risky for the conservation of the wooden ceiling, the proposed weighted function $\Phi$ has pinpointed a HVAC configuration able to further reduce the conservation risk along with the energy saving and the thermal comfort of visitors.

The methodology can be effective only if a thorough knowledge of the indoor climate and its interaction with the objects is reached. Even if the method has been applied to a specific case study, the Archaeological Museum of Priverno (Italy), it can be potentially exploited for other sites in which also other types of degradation are experienced providing that an empirical does-response relationship is available or can be derived from experimental data.

\section{Acknowledgement}

We thank Sapienza University of Rome for funding the multidisciplinary project "Preservation, conservation and valorisation of archaeological sites: The case of the ancient site Privernum". This research has been carried out within the "Renovation of existing buildings in NZEB vision (nearly Zero Energy Buildings)" Project of National Interest (Progetto di Ricerca di Interesse Nazionale - PRIN) funded by the Italian Ministry of Education, Universities and Research (MIUR).

\section{References}

ASHRAE (2011) ASHRAE handbook - HVAC applications. Chapter 23: Museums, galleries, archives, and libraries. American Society of Heating, Refrigerating and Air-Conditioning Engineers, Inc., Atlanta

Barclay, M., Holcroft, N., Shea, A.D. (2014). Methods to determine whole building hygrothermal performance of hemp-lime buildings. Building and environment 80, 204-212.

Camuffo D. (2014). Microclimate for Cultural HeritageConservation, Restoration, and Maintenance of Indoor and Outdoor Monuments. Elsevier. Amsterdam (NL).

Cohen, E.R. (1998). An introduction to error analysis: The study of uncertainties in physical measurements. IOP Publishing.

European Committee for Standardization (2007). Indoor environmental input parameters for design and assessment of energy performance of buildings addressing indoor air quality, thermal environment, lighting and acoustics (EN 15251:2007).

European Committee for Standardization (2010). Conservation of cultural property-procedures and instruments for measuring temperatures of the air and the surfaces of objects (EN 15758:2010).

European Committee for Standardization (2012). Conservation of cultural property-procedures and instruments for measuring humidity in the air and moisture exchanges between air and cultural property (EN 16242:2012).

Frasca F., Cornaro C., Siani A.M. (2018). Performance assessment of a heat and moisture dynamic simulation model in IDA ICE by the comparison with WUFI Plus. IOP Conference Series: Materials Science and Engineering 364, 012024. Florence (IT), 16-18 May 2018.

Frasca, F., Cornaro, C., Siani, A.M. (2019). A method based on environmental monitoring and building dynamic simulation to assess indoor climate control strategies in the preventive conservation within historical buildings. Science and Technology for the Built Environment 25(9), 1253-1268.

Hansen, T.K., Bjarløv S., Peuhkuri R.H., Harrestrup M. (2018). Long term in situ measurements of 
hygrothermal conditions at critical points in four cases of internally insulated historic solid masonry walls. Energy and Buildings 172, 235-248.

Kramer R., van Schijndel J., Schellen H. (2017). Dynamic setpoint control for museum indoor climate conditioning integrating collection and comfort requirements: Development and energy impact for Europe. Building and Environment 118, 14-31.

Kompatscher, K., Kramer, R.P., Ankersmit, B., Schellen, H.L. (2019). Intermittent conditioning of library archives: Microclimate analysis and energy impact. Building and Environment, 147, 50-66.

Legislative Decree 192/2005. Attuazione della direttiva 2002/91/CE relativa al rendimento energetico nell'edilizia pubblicato nella Gazzetta Ufficiale $\mathrm{n}$. 222 del 23 settembre 2005 - Supplemento Ordinario n. 158.

Lucchi, E. (2018). Review of preventive conservation in museum buildings. Journal of Cultural Heritage 29, 180-193.

Martens, M.H.J. (2012) Climate risk assessment in museums: degradation risks determined from temperature and relative humidity data. Doctoral dissertation. Technische Universiteit Eindhoven. Eindhoven (NL).
Mazzarella L. (2015). Energy retrofit of historic and existing buildings: the legislative and regulatory point of view. Energy and Buildings 95, 23-31.

Michalski, S. (2002). Double the life for each five-degree drop, more than double the life for each halving of relative humidity. In Preprints of $13^{\text {th }}$ Meeting of ICOM-CC (pp. 66-72).

O’Leary, T.P., Menzies, G., Duffy, A. (2015). The design of a modelling, monitoring and validation method for a solid wall structure. Energy Procedia 78, 243-248.

Schito, E., Conti, P. and Testi, D. (2018). Multi-objective optimization of microclimate in museums for concurrent reduction of energy needs, visitors' discomfort and artwork preservation risks. Applied Energy 224, pp.147-159.

Webb, A.L. (2017). Energy retrofits in historic and traditional buildings: A review of problems and methods. Renewable and Sustainable Energy Reviews 77, 748-759.

Vereecken E., Van Gelder L., Janssen, H., Roels S. (2015). Interior insulation for wall retrofitting - A probabilistic analysis of energy savings and hygrothermal risks. Energy and Buildings 89, 231244. 